\title{
The patient is the most important member of the team
}

Twenty five years after he had type 1 diabetes diagnosed, Dominick Frosch finds health professionals still fail to treat him as an equal in managing his disease

\section{Dominick L Frosch fellow and associate professor}

${ }^{1}$ Gordon and Betty Moore Foundation, Page Mill Road, Palo Alto, CA 94304, USA; ${ }^{2}$ Department of Medicine, University of California, Los Angeles, USA

In January 1988, just before I turned 17, I was told I had type 1 diabetes. I had to learn to live with and take responsibility for monitoring and managing a chronic disease 24/7, 365 days of the year to prevent complications. ${ }^{12}$ There is no day off.

The Diabetes Control and Complications Trial, which showed that intensive self management could limit and prevent complications of type 1 diabetes, was not published until five years after my diagnosis, ${ }^{3}$ but I was fortunate to get my initial treatment in a forward thinking German hospital that invited me to participate in a training programme. From day 1 I was taught that the management of my diabetes was in my hands. This made sense. I don't live in a doctor's office; nor was I particularly interested in spending a lot of time in one.

The concept of self efficacy-the belief that one is able to adopt a particular behaviour, was described over 30 years ago. ${ }^{4} \mathrm{My}$ training programme instilled the belief that I could manage my diabetes and gave me the confidence to do so. Higher levels of behavioural self efficacy are linked to better outcomes in diabetes and other chronic diseases, ${ }^{5}$ and it's certainly been true in my case.

Much has been written about how to engage and motivate patients to self manage chronic disease. Some of my work as a researcher has touched on this. Wagner's chronic care model assumes that interprofessional teams are better at guiding and motivating patients than single physicians. ${ }^{6}$ But lost in this is how health professionals interact with patients. Over time I've repeatedly found that my concept of a healthcare team-with me as the patient at the centre-is not shared by my healthcare professionals. They don't put me at the centre and often fail to communicate well with one another.

\section{Leading not following}

I love to travel— to see the world-and this has been a key motivator to manage my diabetes well. I schedule an appointment with an ophthalmologist annually. It's always an anxious time, as I fear the detection of the first signs of diabetic retinopathy.

Three years ago, I saw a new ophthalmologist. After a technician had done the initial examinations, I sat in the room waiting for my eyes to dilate. Fifteen minutes later the physician entered the room, introduced herself, turned down the lights, and began her careful examination of my retina. For what seemed like an eternity to me, she examined my eyes without saying a word. Finally, she said, "Everything looks great. I don't see any trace of retinopathy." What a relief, I thought. But what followed startled me. Seemingly wanting to praise me for my efforts, she said: "You must be really good at following orders!"

For a brief moment I considered my retort. I imagined lecturing her on what it means to be patient centred, offering some papers I had written. But I chose to just nod and smile, as so many patients do. ${ }^{7}$ Later I replayed the situation in my mind and kept asking, "Do you really think I do this for you?" I don't check my blood glucose eight times a day to make my physicians happy. I do it because it helps me stay on track and achieve my goals.

The ophthalmologist's comment felt undermining. My success in staving off retinopathy was not my accomplishment so much as the result of following doctor's orders.

\section{Importance of language}

Last year, my glycated haemoglobin $\mathrm{A} 1_{\mathrm{c}}$ result came back at $6.7 \%$, and my primary care physician emailed me to say this reflected "adequate control." Given that the level was below the guideline target of 7.0\%, and my haemoglobin $\mathrm{A} 1_{\mathrm{c}}$ had been at or near this level for as long as I had records and I had no retinopathy or other complications, I deemed this level to represent good control—not merely adequate. Tight glucose management has its downsides. ${ }^{3}$ I've experienced nocturnal seizures as a result of hypoglycaemia, and I injured my shoulder during a severe episode 10 years ago. I know that I want to avoid that risk. 
I decided to reply to my doctor. I clarified the risks of pushing my glucose lower and said that for me a result of $6.7 \%$ was spot on. My physician was gracious enough to reply that she stood corrected. But how many patients would dare to push back like that? Few dare question or disagree with their physician's assessment for they fear it will lead to them being labelled difficult and that might compromise their future care. ${ }^{7}$ Perhaps I am a "difficult" patient. But I'm willing to live with that for the sake of my health.

During my most recent annual ophthalmology examination, which confirmed that I still have no trace of retinopathy, I was again surprised. The process began with questions: Had I noticed any changes in my vision? Did I continue to take my prescribed medicines? I answered "no" to the first question and "yes" to the second. The technician readied her instruments and said, "Now we're going to see whether you are telling the truth." We've made progress in recognising patients' role in the healthcare team, but we have a long way to go to change the attitudes of health professionals. I want to be recognised as the most important member of the team: the one who knows most about living with this disease. I don't follow orders, and I don't lie about what I do to manage my condition; what I do I do for myself. I hope that someday my care will be delivered by a team that has the respect and humility to understand this.
Competing interests: I have read and understood BMJ policy on declaration of interests and have no relevant interests to declare.

This essay is adapted from an article in Collaborative Caring-Stories and Reflections on Teamwork in Health Care, edited by Suzanne Gordon, David L Feldman, and Michael Leonard and published by Cornell University Press.

Provenance and peer review: Commissioned; not externally peer reviewed.

1 Ahola AJ, Groop P-H. Barriers to self-management of diabetes. Diabet Med J 2013;30:413-20.

2 Mühlhauser I, Berger M. Patient education-evaluation of a complex intervention. Diabetologia 2002;45:1723-33.

3 Diabetes Control and Complications Trial Research Group. The effect of intensive treatment of diabetes on the development and progression of long-term complications in insulin-dependent diabetes mellitus. N Engl J Med 1993;329:977-86.

4 Bandura A. Self-efficacy: toward a unifying theory of behavioral change. Psychol Rev 1977;84:191-215.

5 Marks R, Allegrante JP, Lorig K. A review and synthesis of research evidence for self-efficacy-enhancing interventions for reducing chronic disability: implications for health education practice (part II). Health Promot Pract 2005;6:148-56.

6 Wagner EH, Austin BT, Davis C, Hindmarsh M, Schaefer J, Bonomi A. Improving chronic illness care: translating evidence into action. Health Aff Proj Hope 2001;20:64-78.

7 Frosch DL, May SG, Rendle KAS, Tietbohl C, Elwyn G. Authoritarian physicians and patients' fear of being labeled "difficult" among key obstacles to shared decision making. Health Aff Proj Hope 2012;31:1030-8.

Cite this as: BMJ 2015;350:g7767

๑ BMJ Publishing Group Ltd 2015 